\title{
Ushering a New Era in the Management of Hepatitis C in Children with Hematological Disorders
}

\author{
Meena Sivasankaran $^{1} \cdot \mathrm{M}_{\text {Venkatadesikalu }}{ }^{2} \cdot \mathrm{V}_{\text {Mythili }^{2}} \cdot$ Srinivas Sankaranarayanan $^{1} \cdot$ \\ Dhaarani Jayaraman ${ }^{1} \cdot$ Shivani Patel $^{1} \cdot$ Venkateswaran Vellaichamy Swaminathan $^{1}$. \\ Ramya Uppuluri ${ }^{1} \cdot{\text { Revathi } \text { Raj }^{1}}^{1}$
}

Received: 8 January 2018/ Accepted: 3 July 2018/Published online: 17 July 2018

(C) Indian Society of Hematology and Blood Transfusion 2018

\begin{abstract}
Transfusion-transmitted hepatitis $\mathrm{C}$ is a major concern among thalassemia patients. Our aim is to estimate the prevalence of Hepatitis $\mathrm{C}$ infection among thalassemia patients and to assess the treatment response, adverse effects of Peg-interferon based regimen and the new directacting antiviral drugs. Patients with thalassemia receiving regular blood transfusions with positive anti $\mathrm{HCV}$ antibodies during a period from January 2012 to June 2017 were analyzed. Serial HCV viral load and genotype and liver function tests were performed. Peg interferon and Ribavirin were used in patients diagnosed before January 2016 and patients diagnosed after January 2016 were started on the combination of Ledipasvir/Sofosbuvir. Thirty-two patients aged between 2 and 28 years were analyzed. Genotype 1 was the predominant type. Twentyone patients were initiated on Peg Interferon with Ribavirin, and 14 achieved sustained virological response. All of them had increased blood transfusion requirements with significant compliance issues. All eleven patients started on Ledipasvir and Sofosbuvir including 4 undergoing hematopoietic stem cell transplantation and 7 interferon failures showed sustained viral clearance with good compliance. Ledipasvir/Sofosbuvir combination can be safely used in thalassemia patients and in young children. The cost of therapy is less compared to peg interferon based regimen with good compliance and superior efficacy.
\end{abstract}

Meena Sivasankaran

drmeenas1986@gmail.com

1 Department of Pediatric Hematology, Oncology, Blood and Marrow Transplantation, Apollo Cancer Institute, 320 Padma complex, Chennai 600035, India

2 Voluntary Health Services Hospital Thalassemia Center, Chennai, India
Keywords Hepatitis C · Interferon - Ledipasvir and Sofosbuvir $\cdot$ Sustained viral response

$\begin{array}{ll}\text { Abbreviations } \\ \text { HCV } & \text { Hepatitis C virus } \\ \text { AASLD } & \text { American Association for the Study of the Liver } \\ & \begin{array}{l}\text { Disease } \\ \text { EASL }\end{array} \\ \text { European Association for the Study of the Liver } \\ \text { DAAs } & \text { Direct acting anti virals } \\ \text { SVR } & \text { Sustained virological responcse } \\ \text { IFN } & \text { Interferon } \\ \text { LDV } & \text { Ledipasvir } \\ \text { SOF } & \text { Sofosbuvir }\end{array}$

\section{Introduction}

It is estimated that, $12-85 \%$ of thalassemia patients around the world are positive for anti HCV antibodies [1]. Though, rigorous donor screening and advanced testing procedures like nucleic acid test have dramatically reduced the transmission of HCV worldwide, it still remains a major concern in developing countries [2].

In India, almost $20-60 \%$ of thalassemia patients are positive for anti HCV antibodies [1, 3]. Until 2011, Interferon with or without ribavirin was the approved treatment for Hepatitis C, resulting in sustained virological response rates of around 40-60\% [4]. The Direct acting antiviral (DAAs) drugs have currently revolutionized the management of Hepatitis $\mathrm{C}$ and have been found to provide extremely high sustained virological response [5]. Ledispavir with Sofosbuvir combination therapy has been licensed for use by the FDA in adults since October 2014 
and in children $>12$ years from April 2017 [6, 7]. Recently, the American Association for the Study of the Liver Disease (AASLD 2017) guidelines and the European Association for the Study of the Liver (EASL 2015) have recommended that, patients with hemoglobinopathy should be treated with IFN free regimen without ribavirin [5].

A high sustained virological response, improved compliance due to the oral route of administration and lesser side effects have made these DAAs more promising. However there is no data available on its efficacy, safety and dosage in thalassemia patients, we report our experience in our thalassemic patients with HCV infection.

\section{Patients and Methods}

We performed a retrospective analysis to estimate the prevalence and to assess the response to therapy among patients on regular blood transfusion and to compare the side effects and efficacy profile of regimes based on interferon versus new direct-acting antiviral therapy. The case records of patients with thalassemia at the Voluntary Health Services Hospital Thalassemia Center and Apollo Cancer Institute, Chennai during the period from January 2012 to June 2017 were analyzed. In the patients detected to have positive anti-HCV antibodies on annual screening, $\mathrm{HCV}$ viral load, genotype and liver function tests were done serially.

In the patients diagnosed before January 2016, Peg interferon and Ribavirin were initiated and given for a period of 24-48 weeks. In the patients diagnosed after January 2016, a combination of Ledipasvir with Sofosbuvir was administered for 24 weeks. Fixed dose combination of Ledipasvir $90 \mathrm{mg} /$ Sofosbuvir $400 \mathrm{mg}$ (LDV/SOF) is recommended for children $>12$ years, weighing $>35 \mathrm{~kg}$ and it is administered once daily for genotype 1, 4, 5 and 6 [6]. Since there is no information on dosing in younger children, an investigational dosage of Ledipavir, sofosbuvir was arrived and approved by our hospital ethics committee after consultation with concerned specialists. The dosage for children less than 12 years used was: $15-35 \mathrm{~kg}-45 /$ $200 \mathrm{mg},<15 \mathrm{~kg}-22.5 / 100 \mathrm{mg}$.

The response to the treatment was assessed by HCV viral load at the end of three and 6 months of therapy. Complete Response has been defined as absence of HCVRNA at the end of treatment. Sustained Virological response (SVR) has been defined as HCV RNA $<54$ IU/ $\mathrm{ml}, 24$ weeks after treatment (EASL 2011) [4] and for patients received DAAs, SVR defined as undetectable serum HCV RNA 12 weeks after stopping treatment (EASL 2015) [5].

\section{Results}

During the study period of 5 years from January 2012 to June 2017, a total of 215 patients have been on regular follow-up. Forty-seven $(21 \%)$ of these patients were positive for anti HCV antibodies. Of these 39 patients were less than 18 years. The median age of the patients was 15 years (range-2-28). Thirty-two patients were detected to have viral load ranged from 15000 to over 10 million copies. Genotype 1 was the predominant type seen in $28(84 \%)$ patients.

Twenty-one (66\%) patients diagnosed before January 2016 were treated with Peg-Interferon with Ribavirin, and 14 patients $(66.6 \%)$ had achieved sustained virological response. Seven patients (33.4\%) had persistently high viral load despite adequate therapy. All patients on the interferon-based regimen had 1.5 times increase in blood transfusion requirements with significant compliance issues related to antiviral therapy due to subcutaneous route of administration and adverse effects like fever, severe myalgia and acute depression.

Eleven patients (34\%) were started on Ledipasvir and Sofosbuvir (LDV/SOF) combination. Among them four underwent hematopoietic stem cell transplantation and none of them had veno-occlusive disease. Seven patients who had failed or relapsed after interferon therapy were also started on this combination. All 18 patients on LDV/ SOF, including 11 naïve patients and seven interferon failures showed sustained viral clearance with good drug compliance.

The mean SGPT value prior to treatment was $92.3 \mathrm{IU} / 1$ and post treatment was $41.2 \mathrm{IU} / \mathrm{l}$. Our patients had only mild derangement of liver functions due to early detection of raising viral load through periodic screening and none of them had evidence of liver cell failure. The mean ferritin values among these patients prior to therapy were $3000.58 \mathrm{mg} / \mathrm{dl}$. After therapy, the mean ferritin level was $1988.29 \mathrm{mg} / \mathrm{dl}$, showing a $37 \%$ reduction from baseline, reflecting a decrease in inflammation.

\section{Discussion}

The prevalence of HCV among our thalassemic patients on regular blood transfusions is $21 \%$. Of these patients, $70 \%$ had active viral replication proven by a high viral load and Genotype 1 was the most common type found in $84 \%$ of them [8].

The sustained virological response rate among patients treated with Interferon-based therapy was $66 \%$ in our cohort and they had an increase in transfusion requirements, poor compliance, side effects as reported by others $[9,10]$. The cost of therapy for each patient amounted to 
60,000 INR per month. Ledipasvir/Sofosbuvir combination had a superior safety profile, and the cost per patient was 7500 INR per month $[11,12]$.

Despite effective donor screening programs, a significant proportion of patients receiving regular blood transfusion are $\mathrm{HCV}$ positive. There is no vaccination to protect against contracting HCV. Molecular testing for HCV-RNA utilizing nucleic acid amplification technology (NAT) is the most sensitive assay and shortens the window period to only 4 days. Rigorous testing of donated blood, standardization of laboratory screening procedures and implementation of NAT is required to achieve dramatic reductions in transfusion transmitted $\mathrm{HCV}$.

Our study reinforces the need for annual viral screening of patients with thalassemia major and at times when there is sudden increase in serum ferritin. If screening is positive, early testing of viral load and genotype will help offer therapy before the onset of liver disease. DAAs should be considered as a first-line therapy in either naïve or treatment experienced. Widespread access to combinations of DAAs is feasible, and it requires fast regulatory approvals of new drugs, the establishment of national viral hepatitis programs and easy access to the programs [11, 12].

\section{Conclusion}

This is the first report from India on Direct Acting Antivirals in thalassemia patients and also in young children and it is clear that Ledipasvir with Sofosbuvir is safe in children as young as 2 years and can be used during hematopoietic stem cell transplantation. The cost of therapy is 7500 INR per month, which is $88 \%$ less as compared to Peg interferon-based regimen, with good compliance and superior efficacy. This therapy should be recommended in all transfusion-transmitted hepatitis $\mathrm{C}$ including patients undergoing high-dose chemotherapy. We plan to follow up our cohort to document sustained virological response over the next few years.

\section{Compliance with Ethical Standards}

Conflict of interest All authors agree that they have no conflict of interest.

Ethical Approval All procedures performed in studies involving human participants were in accordance with the ethical standards of the institutional and/or national research committee and with the 1964 Helsinki declaration and its later amendments or comparable ethical standards.

Informed Consent Informed consent was obtained from the all the individual patients included in the study.

\section{References}

1. Thalassaemia International Federation (2015) HCV position paper. Viral hepatitis $C$ in thalassaemia, pp 14-15

2. Marwaha N, Sachdev S (2014) Current testing strategies for hepatitis $\mathrm{C}$ virus infection in blood donors and the way forward. World J Gastroenterol: WJG 20(11):2948

3. Di Marco V, Capra M, Angelucci E, Borgna-Pignatti C, Telfer P, Harmatz P, Kattamis A, Prossamariti L, Filosa A, Rund D, Gamberini MR (2010) Management of chronic viral hepatitis in patients with thalassemia: recommendations from an international panel. Blood 116(16):2875-2883

4. Craxi A, Pawlotsky J, Wedemeyer H, Bjoro K, Flisiak R, Forns X, Mondelli M, Peck Radosavljevic M, Rosenberg W, Sarrazin C, Jacobson I (2011) European Association for the Study of the Liver. EASL clinical practice guidelines: management of hepatitis C virus infection. J Hepatol 55(2):245-264

5. European Association for Study of Liver (2015) EASL recommendations on treatment of hepatitis C. J Hepatol 63(1):199

6. Food US (2014) Drug Administration approves Gilead's Harvoni (ledipasvir/sofosbuvir), the first once-daily single tablet regimen for the treatment of genotype 1 chronic hepatitis C. [internet]. Foster City (CA): Gilead Sciences, Inc, p 4. Accessed 25 Nov 2014. http://www.fda.gov/NewsEvents/Newsroom/PressAnnounce ments/ucm $418365 . \mathrm{htm}$

7. Release FN (2017) FDA approves two hepatitis C drugs for pediatric patients. http://www.fda.gov/NewsEvents/Newsroom/ PressAnnouncements/ucm418365.htm

8. Christofidou M, Lambropoulou-Karatza C, Dimitracopoulos G, Spiliopoulou I (2000) Distribution of hepatitis C virus genotypes in viremic patients with beta-thalassemia. Eur J Clin Microbiol Infect Dis 19(9): 728-730

9. Butensky E, Pakbaz Z, Foote D, Walters MC, Vichinsky EP, Harmatz P (2005) Treatment of hepatitis $C$ virus infection in thalassemia. Ann N Y Acad Sci 1054(1):290-299

10. Alavian SM, Tabatabaei SV (2010) Treatment of chronic hepatitis $\mathrm{C}$ in polytransfused thalassaemic patients: a meta-analysis. J Viral Hepatitis 17(4):236-244

11. Afdhal N, Zeuzem S, Kwo P, Chojkier M, Gitlin N, Puoti M, Romero-Gomez M, Zarski JP, Agarwal K, Buggisch P, Foster GR (2014) Ledipasvir and sofosbuvir for untreated HCV genotype 1 infection. N Engl J Med 370(20):1889-1898

12. Hill A, Khoo S, Fortunak J, Simmons B, Ford N (2014) Minimum costs for producing hepatitis $\mathrm{C}$ direct-acting antivirals for use in large-scale treatment access programs in developing countries. Clin Infect Dis 58(7):928-936 